\title{
Direct non-productive HIV-1 infection in a T-cell line is driven by cellular activation state and NFKB
}

\author{
Matthew S Dahabieh ${ }^{1}$, Marcel Ooms ${ }^{2 *}$, Chanson Brumme ${ }^{4}$, Jeremy Taylor ${ }^{4}$, P Richard Harrigan ${ }^{4}$, Viviana Simon ${ }^{2,3}$ \\ and Ivan Sadowski ${ }^{1}$
}

\begin{abstract}
Background: Molecular latency allows HIV-1 to persist in resting memory CD4+ T-cells as transcriptionally silent provirus integrated into host chromosomal DNA. Multiple transcriptional regulatory mechanisms for HIV-1 latency have been described in the context of progressive epigenetic silencing and maintenance. However, our understanding of the determinants critical for the establishment of latency in newly infected cells is limited.

Results: In this study, we used a recently described, doubly fluorescent HIV-1 latency model to dissect the role of proviral integration sites and cellular activation state on direct non-productive infections at the single cell level. Proviral integration site mapping of infected Jurkat T-cells revealed that productively and non-productively infected cells are indistinguishable in terms of genomic landmarks, surrounding epigenetic landscapes, and proviral orientation relative to host genes. However, direct non-productive infections were inversely correlated with both cellular activation state and NFkB activity. Furthermore, modulating NFKB with either small molecules or by conditional overexpression of NFKB subunits was sufficient to alter the propensity of HIV-1 to directly enter a non-productive latent state in newly infected cells. Importantly, this modulatory effect was limited to a short time window post-infection.
\end{abstract}

Conclusions: Taken together, our data suggest that cellular activation state and NFkB activity during the time of infection, but not the site of proviral integration, are important regulators of direct HIV-1 non-productive infections.

Keywords: HIV-1, Latency, LTR, CMV, Promoter, eGFP, mCherry, Double-label, Silent-infection, NFKB

\section{Background}

Integrated HIV-1 provirus transcribes messenger and genomic RNA to produce progeny virions. However, the HIV-1 promoter can also exist in an inactive state, and the subsequent lack of viral products allows latently infected cells to escape both immune surveillance and viral cytopathic effects (reviewed in [1-3]). Importantly, latent HIV-1 remains functional and can be reactivated by cellular activation, for example. This results in proviral transcription and production of new virions [4]. Thus, HIV-1 latency, which allows the virus to persist indefinitely during highly active antiretroviral therapy (HAART), is one of the most significant barriers to HIV-1 eradication.

\footnotetext{
* Correspondence: marcel.ooms@mssm.edu

${ }^{2}$ Department of Microbiology, The Global Health and Emerging Pathogens Institute; Mount Sinai School of Medicine, 1468 Madison Avenue, Annenberg building 18-50, New York, NY 10029, USA

Full list of author information is available at the end of the article
}

HIV-1 latency is generally regarded as a product of proviral transcriptional silencing. Numerous silencing mechanisms have been characterized using in vitro latency models that require cellular activation and longterm culturing to identify and isolate latently infected cells. Given these requirements, the majority of known silencing mechanisms pertain to the progressive silencing of productive infections and the maintenance of a latent state. Nevertheless, known HIV-1 transcriptional silencing mechanisms include: 1) suboptimal T-cell activation, 2) low levels of transcriptional activator function, 3) restrictive chromatin structure at the site of integration, 4) transcriptional interference at the site of integration, 5) low pTEF-b (CDK9/Cyclin T1) levels, and 6) repressive HIV-1 LTR nucleosome positioning and histone post-translational modifications (reviewed in [1-3]).

Without the ability to identify latently infected cells early, and in the absence of activation stimuli, it is 
difficult to evaluate which HIV-1 transcriptional silencing mechanisms are critical for latency establishment in newly infected cells. Thus, we and others have recently developed double-labeled HIV-1 latency models that can detect both productive and non-productive proviral states early post-infection [5,6]. Application of these models to both cell lines and activated primary CD4+ T-cells suggests that direct non-productive infections (latency) actually represent the majority of HIV-1 infections [5,6]. This conclusion is further supported by other studies identifying silent/inducible infections early in infection $[7,8]$. Taken together, these studies provide significant support for the role of direct silencing in HIV-1 latency establishment, and highlight the importance of studying establishment mechanisms in newly infected cells.

In this study, we use our doubly fluorescent HIV-1 reporter [5] to directly evaluate potential mechanisms responsible for the formation of direct non-productive states in newly infected Jurkat T-cells. We focus on two highly variable HIV-1 transcriptional regulatory mechanisms: 1) proviral integration site, and 2) cellular activation state and NFkB signaling. First, we show that direct non-productive infections occur at all sites of integration, thereby excluding a role for viral integration site locations. Instead, the occurrence of non-productive infections was inversely correlated with cellular activation state and $\mathrm{NF}_{\kappa} \mathrm{B}$ activity. Moreover, modulating $\mathrm{NF}_{\kappa} \mathrm{B}$ levels at the time of infection, either by small molecules or NFkB subunit overexpression, was sufficient to alter the occurrence of non-productive infection in newly infected cells. Taken together, our data suggest that the cellular level of $\mathrm{NF}_{\kappa} \mathrm{B}$ activity at the time of infection, rather than the site of viral integration, controls the establishment of HIV-1 latency in newly infected T-cell lines. These findings are of relevance to HIV-1 eradication strategies since they may point to putative targets for therapeutic interventions minimizing HIV-1 latency establishment rather than latency reactivation.

\section{Results}

The doubly labeled Red-Green-HIV-1 (RGH) molecular clone is a recently described model that enables investigation of HIV-1 transcriptional regulatory mechanisms in newly infected, native state cells. This single-cycle vector incorporates both an LTR-driven gag-eGFP marker, and a CMV-driven mCherry marker in place of Nef, to allow for identification of both productively $(\mathrm{eGFP}+\mathrm{mCherry}+)$ and non-productively (eGFP- mCherry+) infected cells at single cell resolution (Figure 1A, [5]). We have previously used this vector to determine that the majority of HIV-1 proviruses are directly silenced shortly after infection in both cell lines and primary CD4+ T cells [5]. Since the majority of HIV-1 latency mechanisms described pertain to progressive epigenetic silencing, the determinants of direct non-productive infection remain unknown. In this study, we sought to use the recombinant RGH model to dissect the roles of proviral integration site and cellular activation state in regulating direct non-productive infection in Jurkat T-cells.

\section{Both productive and non-productive HIV-1 proviruses are integrated at similar locations}

HIV-1 proviral integration sites are highly variable $[1-3,9,10]$. In some latency models, proximity to certain genomic features (alphoid repeats - [11], gene deserts [12], and very highly expressed genes $[7,12]$ ) has been associated with proviral transcriptional silencing. However, a recent meta-analysis of integration sites found that, in five distinct latency models using either celllines or primary T-cells, these associations are not universal properties of HIV-1 latency, but rather are specific to the models in which they were identified [13]. Importantly, this study highlights the importance of characterizing the effect of integration site in each individual latency model. In this light, we sought to determine whether proviral integration sites were different between productively and non-productively RGH-infected Jurkat cells. We sorted total RGH infected cells into non-productively infected 'red' (eGFP- mCherry+; $4 \%$ of total), and productively infected 'yellow' (eGFP+ mCherry+; $\sim 2 \%$ of total) cell populations with more than $90 \%$ purity (Figure 1B). The 'double negative' population (eGFP- mCherry-) was also sorted and analyzed since we previously estimated that $\sim 30 \%$ of all RGH infections result in direct repression of both the LTR and CMV promoters [5]. To identify sites of viral integration, genomic DNA from each population was extracted, digested with $M s e I$, and ligated to adapters [14]. Nested PCR was used to amplify LTR-host chromosome junctions and resulting amplicons were sequenced by 454 pyrosequencing [14]. Reads were filtered for quality and mapped to the human genome using the INSIPID pipeline [15].

We mapped 2,900 and 4,271 unique integration sites in the 'red' and 'yellow' populations, respectively. Consistent with our previous characterization of 'double negative' RGH infected cells [5], we were also able to map 1,195 integration sites in this population, which represent proviruses in which both eGFP and mCherry markers were silenced directly upon infection.

To compare the integration sites between the cell populations, we first compared the density of integrations (1 Mb windows) across the whole human genome. Highresolution mapping of the integrations found within chromosome one, as well as within the entire human genome, revealed that in all cell populations integrations were largely constrained to gene dense areas, and that the integration densities in all three cell populations 


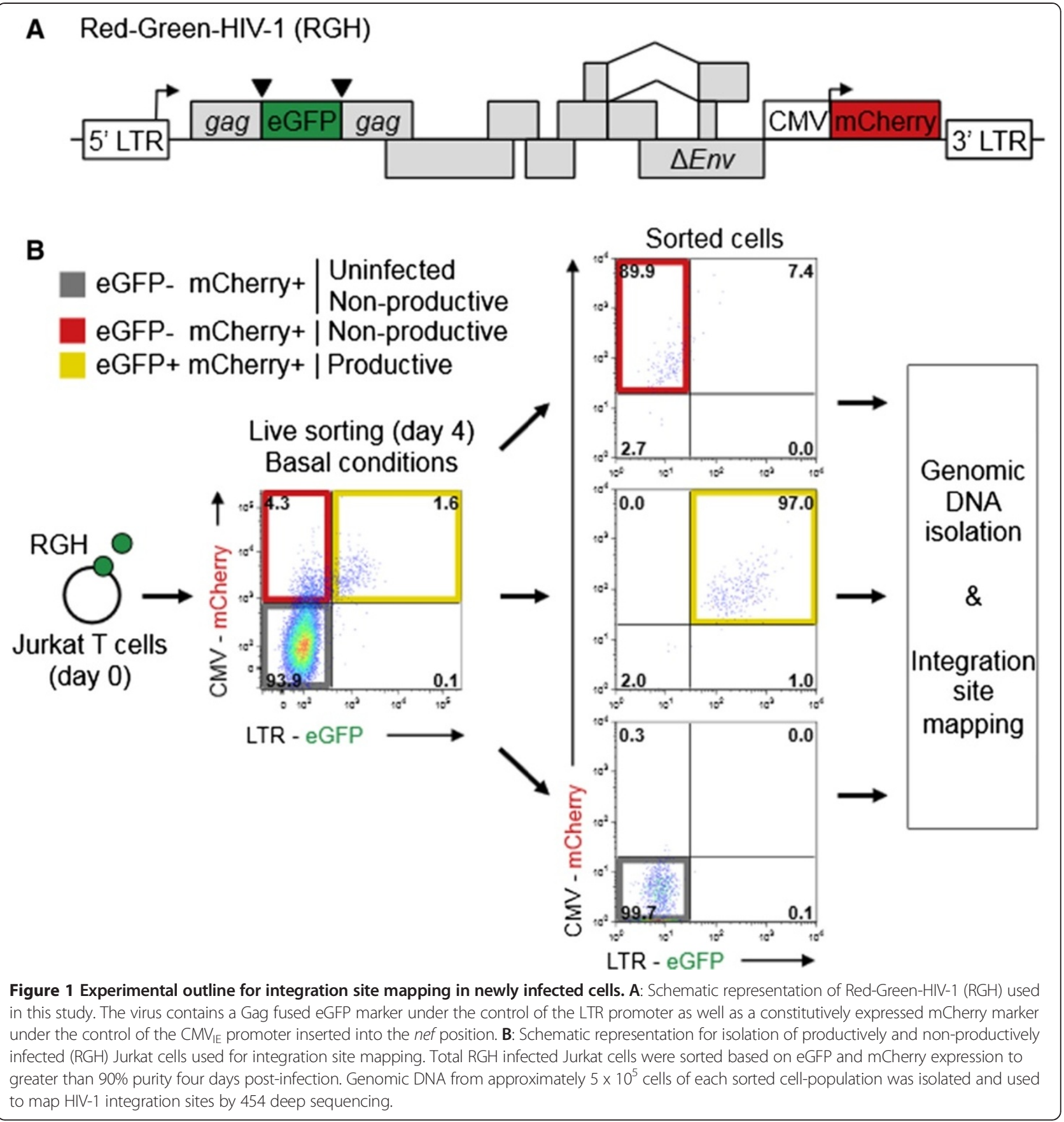

were largely overlapping (Figure 2A). Quantification of integration sites and gene densities showed a highly significant correlation for each population (Spearman correlation, 'double negative', rho $=0.78$; 'red', rho $=0.83$; 'yellow', rho $=0.85 ; \mathrm{p}<0.001$ in all cases, Figure 2B). This preference for HIV-1 integrations in gene-rich areas is consistent with previous reports $[9,10]$. Quantification of integration density across the genome revealed similar integration site distributions for each of the 'double negative', 'red', and 'yellow' populations (Figure 2C). Of note, we did observe a minor but statistically significant decrease in integration density for the 'red' population in chromosome 18 (Figure $2 \mathrm{C}-\mathrm{p}<0.05$ ). We also observed a modest but statistically significant increase in integrations into chromosomes 3 and 16, and a decrease in integrations into chromosome 6 for the 'double negative' population (Figure $2 \mathrm{C}-\mathrm{p}<0.05$, ANOVA for number of integrations in each chromosome, and Student's $\mathrm{T}$ test for number of 'double negative' integrations compared to 'red' and 'yellow' populations). 


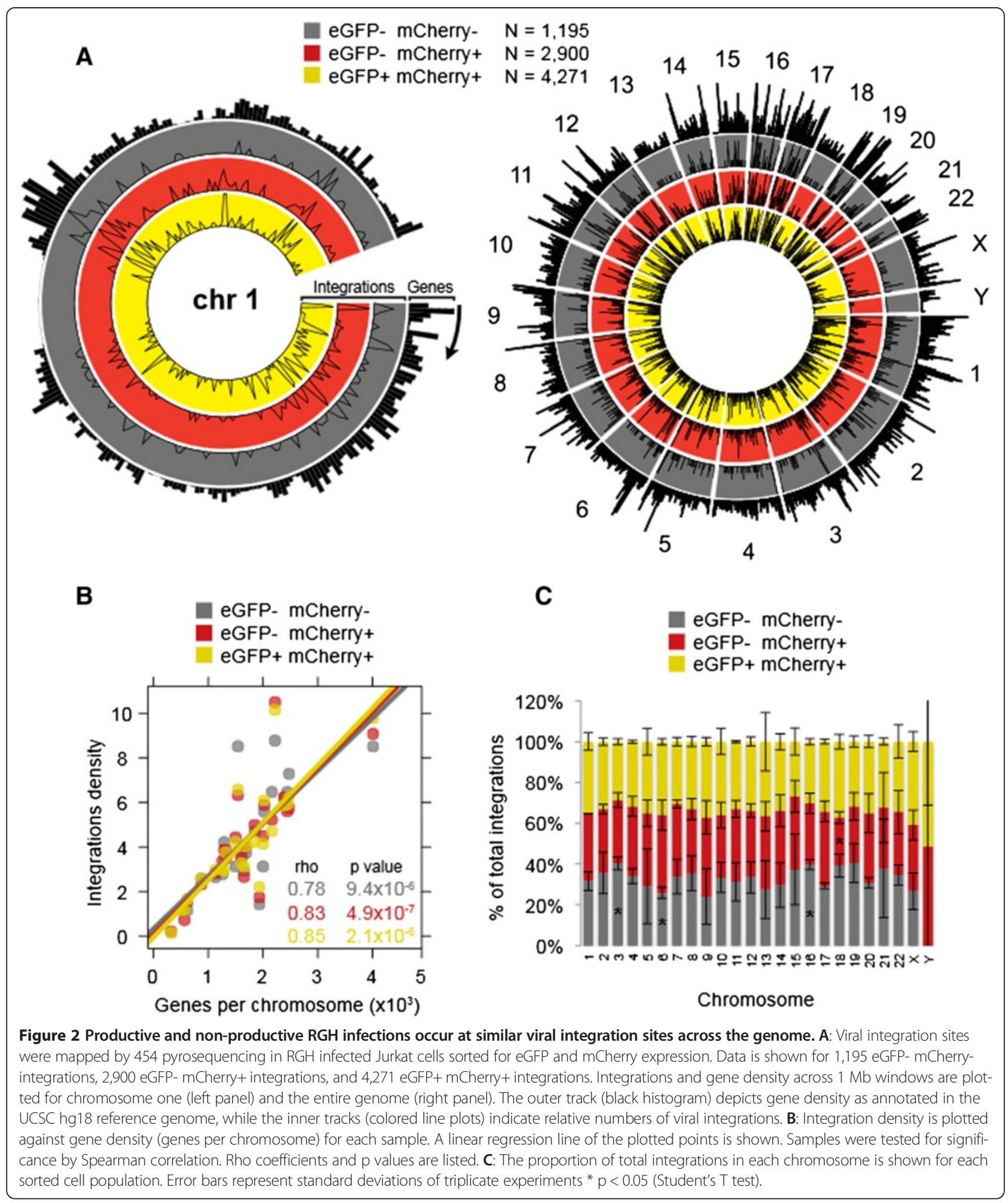

High-throughput analysis of HIV-1 integration sites has previously revealed genomic preferences for HIV-1 integration in terms of gene density, distance to gene boundaries and transcriptional start sites (TSS), DNaseI hypersensitivity, CpG density, gene expression, and GC content $[9,10]$. Each of these characteristics are indicative of HIV's preference to integrate into nucleosome-associated DNA within the introns of actively transcribed genes $[9,10]$. We used the INSIPID pipeline (Bushman Lab, University of Pennsylvania) to compare the genomic signatures of integration between 
each RGH infected population (Figure 3A). As a whole, the genomic properties of integrations in each population were consistent with previous studies $[9,10]$, indicating that the RGH virus integrates into host chromatin similarly to wild type HIV-1. Importantly, the genomic signatures of the integration events in the 'red' population were highly similar to those in the 'yellow' population, indicating that they do not affect non-productive and productive infections (Figure 3A). Of note, we did observe a minor, but significant decrease in intergenic space ('intergenic width' - Figure 3A, p $<0.05$, Wald test), and association with highly expressed genes ('top $1 / 2$ expr. $1 \mathrm{Mb}$ Unigene' - Figure 3A, p < 0.05, Wald test), suggesting that integrations in the 'red' population (non-productive infections) may be located in slightly less gene dense and less expressed regions than in the 'yellow' population. The profile of integrations in the 'double negative' population were similar to the 'red' and 'yellow' populations but the number of integrations into genes (coding or intronic sequence and irrespective of expression) was significantly increased ('in gene, refSeq' - Figure 3A, $\mathrm{p}<0.001$, Wald test; 'gene expr. $1 \mathrm{Mb}$, Unigene' Figure $3 \mathrm{~A}, \mathrm{p}<0.05)$. These findings suggest that, in certain contexts, integration into genes could repress transcription of both the LTR and CMV promoters in the RGH provirus ('double negative' population). Of note, the gene expression profiles used in this analysis were obtained from previous independent datasets produced with Jurkat cells [16].

We also compared the epigenetic landscape surrounding viral integration sites in the different $\mathrm{RGH}$ infected populations using INSIPID's annotated epigenetic data from independent Jurkat and CD4+ T-cell experiments [15,17-23]. No significant differences were observed between the 'red' and 'yellow' populations (Additional file 1: Figure S1A). Integrations in the 'double negative' population were, however, significantly less frequently associated with nucleosomes and histone post-translational modifications, as compared to the 'red' or 'yellow' populations (Additional file 1: Figure S1A). This result, and the increased association with genes for the 'double negative' population (Figure 3A), suggests some effect of integration site on

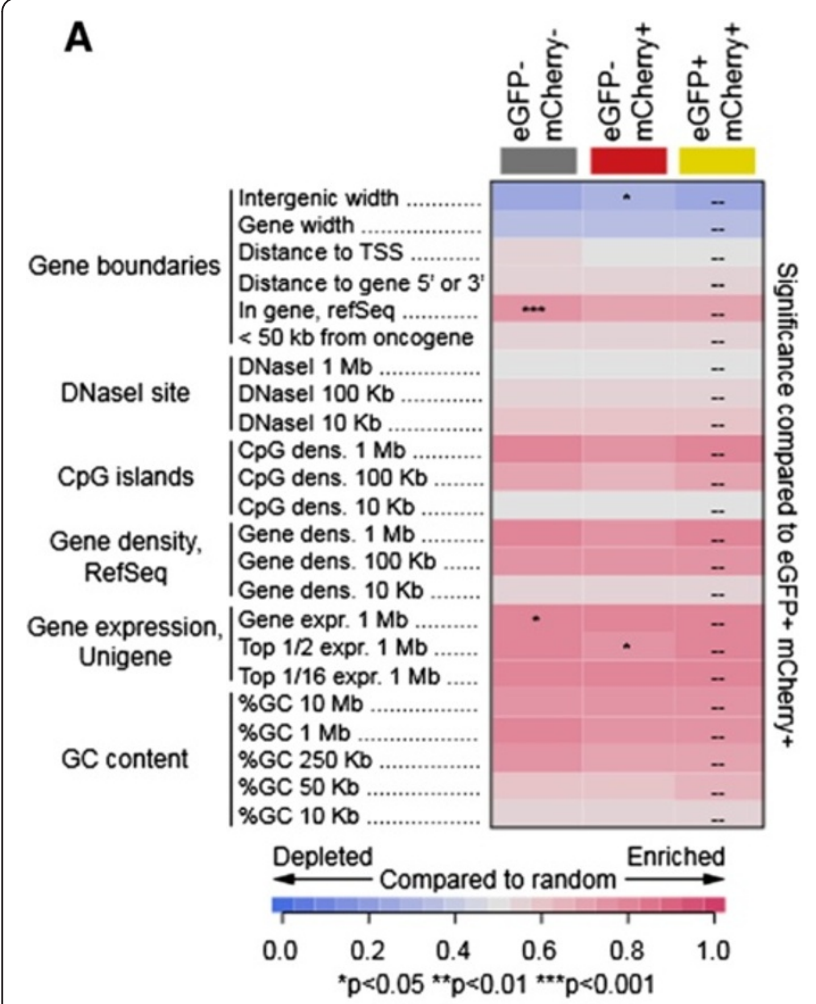

B

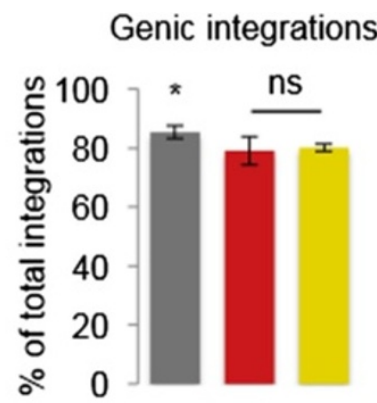

\section{Anti-parallel integrations}
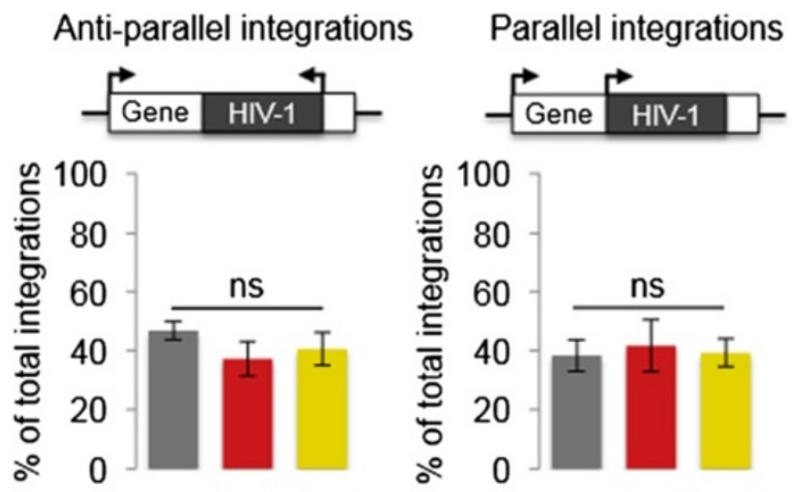

eGFP- mCherry-

eGFP- mCherry+

eGFP+ mCherry+

Figure 3 Productive and non-productive RGH infections are indistinguishable in terms of genomic features at the site of integration, as well as proviral orientation. A: Integration sites in each of the eGFP- mCherry-, eGFP- mCherry+, and eGFP+ mCherry+ samples were compared using the INSIPID heatmap tool for genomic features (Bushman Lab, University of Pennsylvania). Pink and blue colors represent enrichment and depletion of each feature, respectively, relative to matched random controls of integration sites. Statistical significance (ranked Wald tests) is shown relative to the eGFP+ mCherry+ population (dashes). B: The proportion of genic (top panel), anti-parallel (bottom left panel) and parallel (bottom right panel) integrations relative to total integrations is shown for each of the eGFP- mCherry-, eGFP- mCherry+, and eGFP+ mCherry+ infected cells. Error bars represent one standard deviation between triplicate experiments. ' $n s^{\prime}$ non-significant; * $p<0.05$ (Student's T test). 
transcriptional repression. However, this effect is small and likely does not explain the transcriptional differences between the different RGH infected populations. Moreover, this is likely not an HIV-1 specific effect since both the LTR and CMV promoters are silenced in the 'double negative' population.

In human cells, the occurrence of transcriptional regulation-associated histone marks is often correlated with nucleosome position relative to gene promoters and gene bodies [17]. Therefore, we plotted RGH integration densities as a function of both the average distance across genes and the average distance from gene transcriptional start sites (TSS), however we observed no differences between cell populations in either case (Additional file 1: Figure S1B).

We next experimentally tested the effect of the epigenetic landscape on the productivity of RGH infection by utilizing an N74D capsid mutant that causes integration into regions of lower gene density and increased heterochromatin [24-26]. However, no differences were observed in the ratio of non-productive ('red') to productive ('yellow') infections between the RGH N74D capsid mutant and the wild-type RGH vector, further suggesting that epigenetic profiles surrounding integration sites are not major mediators of direct non-productive infection (Additional file 1: Figure S1C).

The orientation of proviral integrations within host genes has also been implicated in HIV-1 transcriptional regulation and latency [27-29]. However, another study did not observe a role for proviral orientation across multiple latency models [13]. Therefore, we compared the frequency of parallel and anti-parallel genic integrations between the RGH infected cell populations. The frequency of parallel and anti-parallel intragenic orientations were similar ( $40 \%$ of total integrations), and not significantly different between cell populations (Figure 3B). Supplementary to proviral orientation, we analyzed the nucleotide sequences around the site of integration in RGH infected cells. These sequences were similar between cell populations and consistent with previously described HIV-1 target sites [9] (Additional file 2: Figure S2A). Moreover, gene ontology analysis did not reveal any differences in the types of genes harboring integrated provirus between the RGH infected cell populations (Additional file 2: Figure S2B).

Taken together, our data suggests that integration sites fail to play a significant role in regulating direct nonproductive RGH infections in newly infected Jurkat cells. Therefore, alternative mechanisms are likely to dictate this process in this model T-cell system.

\section{Direct non-productive HIV-1 infection is associated with lower cellular activation and NFKB signaling}

HIV-1 transcription is tightly linked to both cellular activation and the activity of signaling pathways downstream of the T-cell receptor (reviewed in [1,3]). Moreover, the NFKB pathway is an important and potent regulator of
HIV-1 transcription (reviewed in [30]), and has been previously implicated in mediating early productive HIV-1 infections [7]. Given that direct non-productive RGH infection is independent of proviral integration sites (Figures 2 and 3, S1 and S2), we speculated that differences in cellular activation state and NFKB signaling around the time of infection could be responsible.

To analyze the effect of cellular activation on nonproductive RGH infection we measured CD69 expression, a well characterized early T-cell activation marker [31], in the different populations of RGH infected cells. Staining total RGH infected cells for CD69 early post-infection (four days) showed that the gated 'red' and 'yellow' populations expressed approximately 2.3 and 4.5 fold more CD69 than mock-infected cells, respectively (Figure 4A). In contrast, the gated 'double negative' population (uninfected and eGFP- mCherry- infected cells) expressed CD69 at levels similar to the mock-infected cells (Figure 4A). Importantly, RGH infection itself did not activate Jurkat cells, as we did not observe substantial differences in CD69 expression between the total RGH infected population and mock infected cells (Additional file 3: Figure S3A). These data suggest that differences in LTR transcription from proviruses in newly infected cells are, in fact, associated with differences in cellular activation state.

To specifically address the role of NFKB in the establishment of direct non-productive infections, we infected cells with $\mathrm{RGH}$ and examined NFKB levels four days postinfection by intracellular staining for the DNA-binding p50 subunit of $\mathrm{NFKB}_{\mathrm{K}}$ and the activated form of the transactivating p65 subunit (S529-phospho) (Figure 4B). Both NFkB subunit levels were positively correlated with active transcription, as the gated 'red' and 'yellow' populations expressed approximately 1.3 and 1.5 fold more of both subunits, respectively, whereas the 'double negative' population expressed the lowest levels of both subunits (Figure 4B). Of note, expression of p50 and p65-S529-phospho increased concomitantly in 'red' and 'yellow' cells, suggesting that productive infections are associated with higher cellular levels of the activating form of $\mathrm{NF}_{\mathrm{K} B}$ (p65-p50) rather than the inhibitory p50-p50 form (Figure 4B). Importantly, RGH infection does not appear to up regulate $\mathrm{NF}_{\mathrm{K} B}$, as the total $\mathrm{RGH}$ infected population and mock infected cells expressed similar amounts of both $\mathrm{NFKB}_{\mathrm{K}}$ subunits (Additional file 3 : Figure S3B).

To futher evaluate the role of $\mathrm{NF} \mathrm{KB}$ signaling in promoting productive infection in newly infected cells, we simultaneously monitored both HIV-1 transcription as well as NFKB signaling at the single cell level. We created an RGH isogenic clone bearing the blue fluorescent protein tagBFP in place of eGFP (Red-Blue-HIV-1, RBH), as well as five Jurkat $\mathrm{NF}_{\kappa} \mathrm{B}$ reporter cell lines bearing integrated eGFP constructs under the control of an $\mathrm{NFKB}$ responsive promoter (Figure $4 \mathrm{C}$ ). Infection of Jurkat cells with $\mathrm{RBH}$ 


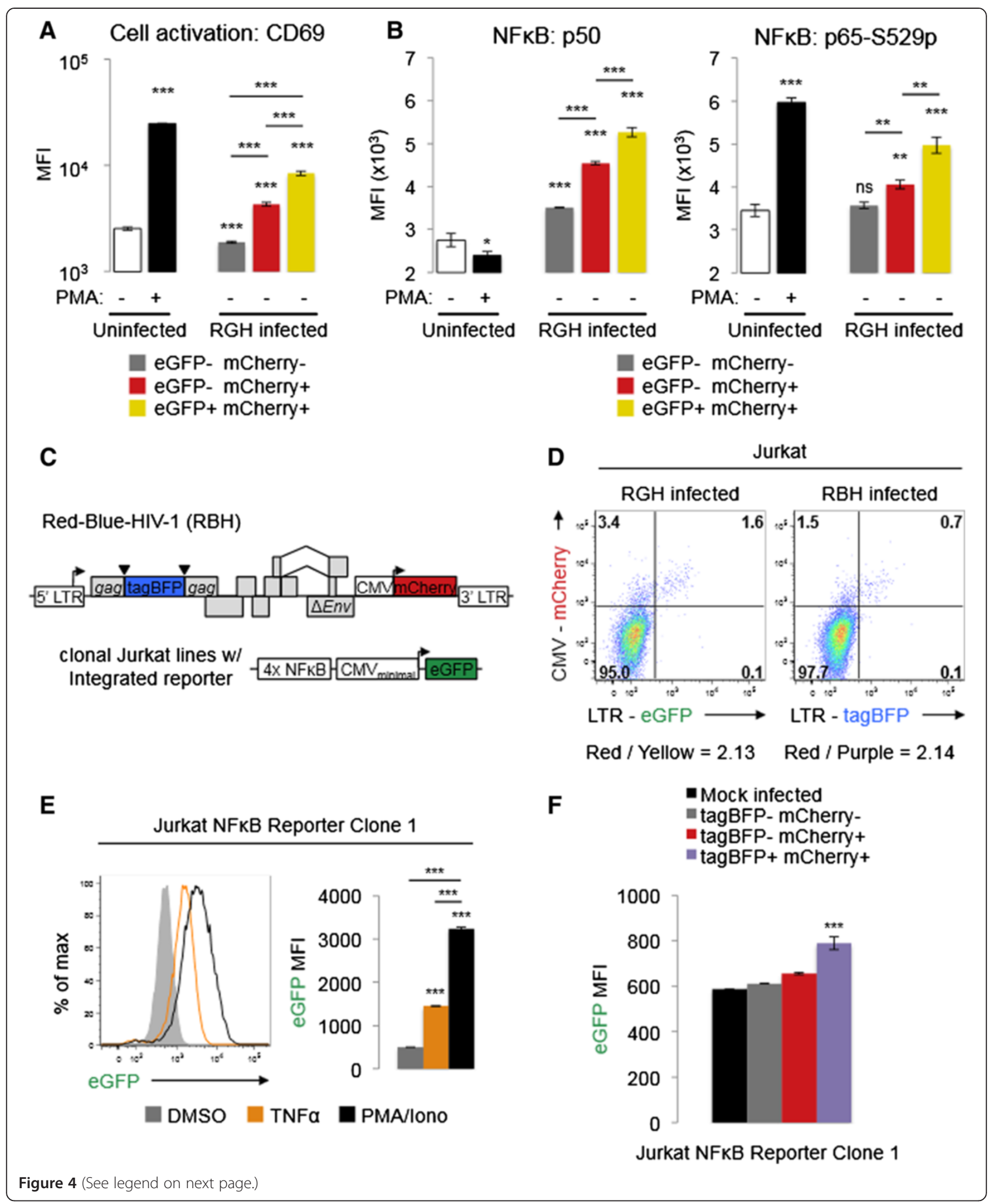


(See figure on previous page.)

Figure 4 Non-productive RGH infection inversely correlates with both cellular activation and NFKB activity. A: RGH infected Jurkat cells (four days post-infection) were assayed for cellular activation by staining with anti-CD69 antibodies and analysis by flow cytometry. Uninfected cells were treated with either DMSO or PMA/lonomycin for 24 hours prior to analysis. Error bars represent standard deviations of triplicate experiments. ${ }^{*} p<0.05$, *** $p<0.001$ (Student's T test). B: Four days post-infection, RGH infected Jurkat cells were stained for NFkB p50 (left panel) and p65-S529-phospho (right panel) subunits and analyzed by flow cytometry. Uninfected cells were treated with DMSO or PMAlonomycin for 30 min prior to analysis. Error bars represent standard deviations of triplicate experiments. 'ns' non-significant, ${ }^{*} p<0.05$, ${ }^{* *} p<0.01,{ }^{* * *} p<0.001$ (Student's T test). C: Schematic representation of Red-Blue-HIV-1 (RBH) and NFKB-eGFP reporter cell lines. RBH contains tagBFP in place of eGFP but is otherwise isogenic. Jurkat NFKB reporter cell lines contain a stably integrated eGFP marker driven by an NFKB responsive promoter (4x tandem NFKB cis-elements 'GGGACTTCC' upstream of a CMV minimal promoter). D: Jurkat cells were infected with comparable amounts of RGH and RBH viral stocks. Cells were analyzed by flow cytometry four days post-infection. Plots shown are representative of multiple independent infection experiments. E: Jurkat NFkB reporter clone 1 was treated with DMSO, TNFa, or PMA/lonomycin for 24 hours prior to analysis by flow cytometry for eGFP mean fluorescence intensity (MFI). Error bars represent one standard error of the mean. ${ }^{* * *} p<0.001$ (Student's T test). F: Jurkat NFkB reporter clone 1 was infected with RBH and analyzed by flow cytometry at four days post-infection. Cells were gated into their constituent infected populations and then analyzed for eGFP MFI. Error bars represent one standard error of the mean. ${ }^{* * *} p<0.001$ (Student's T test).

resulted in an infection profile similar to that of RGH i.e. the majority of $\mathrm{RBH}$ infections resulted in direct nonproductive infection (Figure 4D). Treatment of the NFKBeGFP reporter cell lines with known $N_{\kappa} B$ agonists TNF $\alpha$ and PMA/Iono resulted in 2.2 and 3.7 fold increases in eGFP mean fluorescence intensity (MFI), respectively (Figure 4E, Additional file 4: Figure S4A). Infection of the NFKB reporter cell lines with $\mathrm{RBH}$ virus showed that the productively infected cells (tagBFP + mCherry+, 'purple') were characterized by higher eGFP MFI (indicative of active $\mathrm{NF} \mathrm{B}$ signaling) compared to non-productively infected cells (tagBFP- mCherry+ 'red', or tagBFP- mCherry- 'double negative', Figure 4F - clone 1, Additional file 4: Figure S4B - clones 2-4). Importantly, $\mathrm{RBH}$ infection itself did not up regulate $\mathrm{NF}_{\mathrm{K}} \mathrm{B}$, as we did not observe substantial differences in eGFP fluorescence intensity between $\mathrm{RBH}$ - and mockinfected total cells (Additional file 3: Figure S3C). These data are consistent with the results of the intracellular NFKB staining of RGH infected Jurkat cells, and lend further support to the role of $\mathrm{NF}_{\mathrm{K}} \mathrm{B}$ in regulating early $\mathrm{RGH}$ productive infections.

\section{NFKB modulating drugs administered at the time of infection can alter the occurrence of productive RGH infection}

Our data indicate that cellular activation and NFKB signaling may influence the occurrence of direct non-productive infections in RGH infected cells (Figure 4). Therefore, we hypothesized that modulating $\mathrm{NF}_{\mathrm{B}} \mathrm{B}$ activity during infection would affect the formation of direct non-productive infections. To test this, we treated Jurkat cells with TNF $\alpha$ (NFאB signaling agonist), BMS-345541 (IкB kinase inhibitor), SAHA (HDAC inhibitor) or DMSO (control) during $\mathrm{RGH}$ infection. The infected cells were cultured for three days, treated with either DMSO or PMA/Iono for 24 hours, and then analyzed by flow cytometry.

Cells treated with the DMSO control at the time of infection showed the typical higher frequency of nonproductively infected cells compared to productively infected cells ('red-yellow ratio' $\sim 1.7$ - Figures 5A and B).
Subsequent treatment with PMA/Iono prior to flow cytometry strongly induced LTR expression, resulting in an increase in productively infected cells ('red-yellow ratio' $\sim 0.7$, Figures $5 \mathrm{~A}$ and $\mathrm{B}$ ). In contrast, TNF $\alpha$ treatment at the time of infection reduced the number of non-productively infected cells by $\sim 2.3$ fold ('red-yellow ratio' $\sim 0.7$ ), indicating that $\mathrm{NF} \mathrm{B}$ up regulation during infection largely mitigates the formation of direct nonproductive infection. Furthermore, TNF $\alpha$ treatment at the time of infection prevented LTR transcriptional silencing days later, as PMA/Iono treatment prior to analysis had no further effect in reducing the proportion of non-productively infected cells (Figures 5A and B). TNF $\alpha$ treatment at the time of infection increased the total number of both productive and non-productive infections, suggesting that proviruses present in the 'double negative population' were shifted to productive ('yellow') and non-productive ('red') infections (compare DMSO to TNF $\alpha$ treatment, Figure 5A). Of note, similar effects were observed with PMA/Iono pre-treatment which, in addition to other effects, stimulates NFkB activity in cells (data not shown). Conversely, down regulation of NFKB by BMS-345541 treatment at the time of infection resulted in a $\sim 2.7$ fold increase in the frequency of non-productive infections ('red-yellow ratio' $\sim 4.4$, Figure $5 \mathrm{~A}$ and $\mathrm{B}$ ). This increase in non-productive infections was counteracted by subsequent PMA/Iono treatment prior to flow cytometry, which increased productive infections by $\sim 4.1$ fold ('red-yellow ratio' $\sim 1.1$, Figure $5 \mathrm{~A}$ and $\mathrm{B}$ ). Interestingly, treatment with the HDAC inhibitor SAHA did not mitigate the formation of direct non-productive infection ('red-yellow ratio 1.5 , Figure $5 \mathrm{~A}$ and $\mathrm{B}$ ), despite being a known activator of LTR transcription in other experimental settings [32,33]. This is consistent with previous reports [7], and suggests that epigenetic modifications, such as acetylation (sensitive to the HDAC1 inhibitor SAHA), are likely not a major mediator of direct non-productive infections. Indeed, SAHA (and HDAC inhibitors in general) modulates 


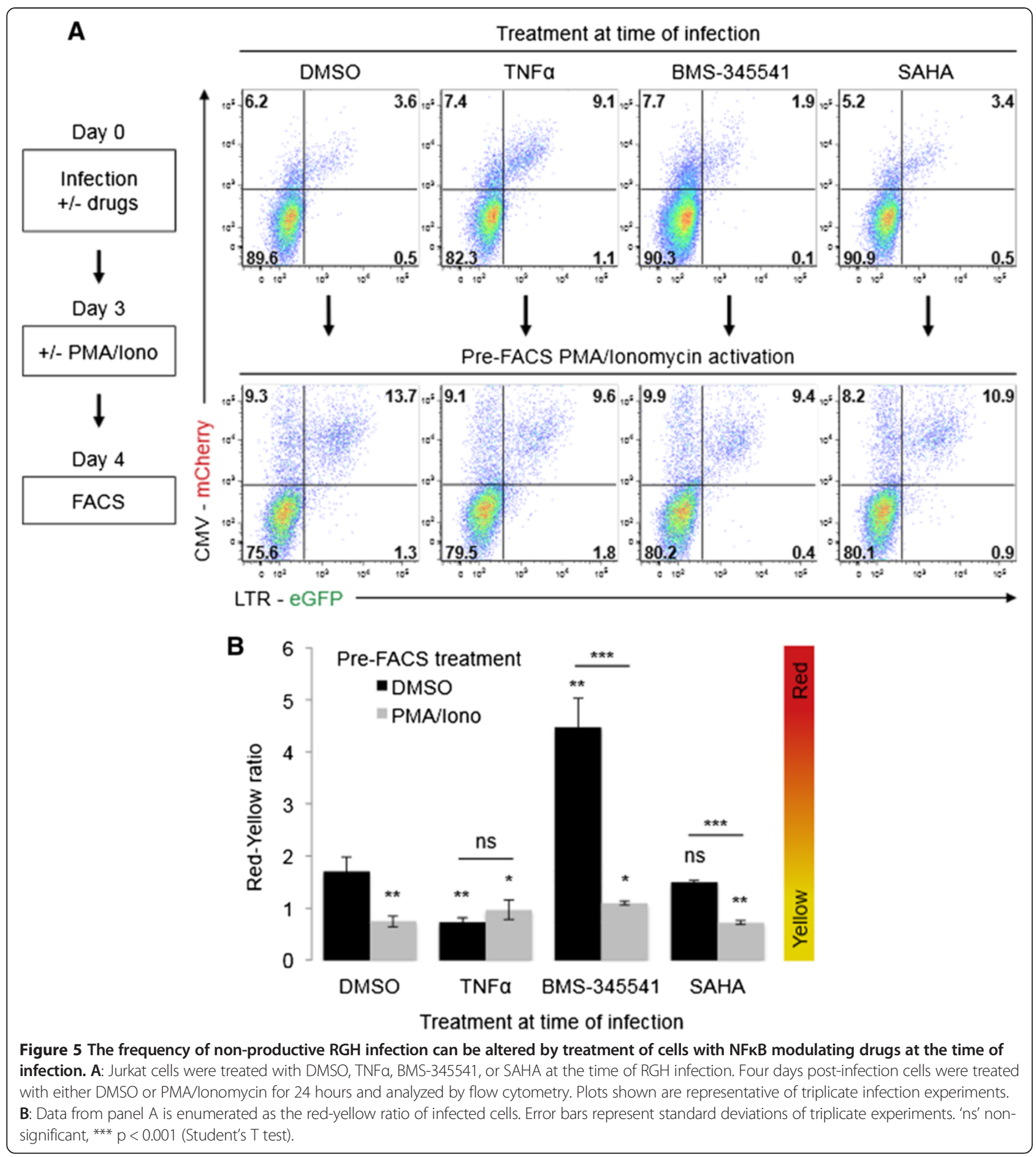

approximately $10-20 \%$ of genes non-specifically without affecting $T$ cell receptor pathways [34].

Taken together, these results suggest that direct nonproductive $\mathrm{RGH}$ infection is regulated by the action of $\mathrm{NF}_{\kappa} \mathrm{B}$ signaling at the time of infection and that the propensity to form a non-productive infection can be modulated by NFKB agonists (TNF $\alpha$ and PMA/Iono) and antagonists (BMS-345541).
Specifically modulating NFKB is sufficient to modulate the occurrence of productive RGH infection

While the major target of TNF $\alpha$ signaling is NFkB, TNF $\alpha$ can also affect the stress response related JNK-MAPK pathway and its downstream factor AP-1 (reviewed in [35]). Although TNF $\alpha$-mediated reduction of RGH latency can likely be attributed to $\mathrm{NF}_{\kappa} \mathrm{B}$ (Figures 4 and 5), it is possible that other pleiotropic effects may be contributing to the 
observed results. To test $\mathrm{NF}_{\kappa} \mathrm{B}$ signaling in a more specific and temporal fashion, we generated Jurkat cell-lines bearing doxycycline inducible versions of a dominant negative (DN) form of the IkB $\alpha$ repressor (S32A/S36A - [36]), or the NFkB p65 subunit to allow direct down- or up-regulation of $\mathrm{NFKB}$ signaling, respectively.

We infected Jurkat cells containing the doxycycline inducible constructs with RGH and cultured the cells in the presence of doxycycline for 24 hours (day 1 to day 2 postinfection). Cells were washed and cultured in fresh complete media until flow cytometry at four and seven days post-infection (Figure 6A). Expression of DN IkB $\alpha$ resulted in a $\sim 1.8$ fold increase in the occurrence of non-productive infections, relative to empty vector control cells ('red-yellow

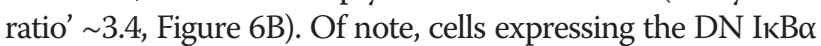
construct showed a $\sim 1.5$ fold increase in non-productively infected cells even in the absence of doxycycline ('red-yellow ratio' 2.9, Figure 6B), which suggests leaky expression of the $\mathrm{DN}$ IкB $\alpha$ construct. In contrast to $\mathrm{DN}$ ІкB $\alpha$, cells expressing the p65 expression construct resulted in a $\sim 2.6$ fold decrease in the proportion of non-productively infected cells, relative to the empty vector control ('red-yellow ratio' $\sim 0.7$, Figure $6 \mathrm{~B}$ ). Importantly, these changes in productively and non-productively infected cells persisted even when cells were cultured in the absence of doxycycline for an additional three days (day 7 post-infection, Figure 6B). These results suggest that modulating NFKB near the time of infection exerts a lasting effect on the establishment of direct non-productive infections and that the observed effects are not due to continual modulation of NFKB signaling. To further test this, we measured IкB $\alpha$ and p65 levels by immunoblotting at two, four, and seven days post infection. Concurrent with the end of doxycycline treatment, we observed a transient increase in IKB $\alpha$ and p65 protein levels at day two post-infection (Figure 6C). This increase was specific to cells containing the expression construct and treated with doxycycline (Figure $6 \mathrm{C}$ ). IкB $\alpha$ and p65 protein levels decreased substantially in the absence of doxycycline treatment four days post-infection, and returned to baseline at seven days post-infection (Figure 6C). Importantly, cells

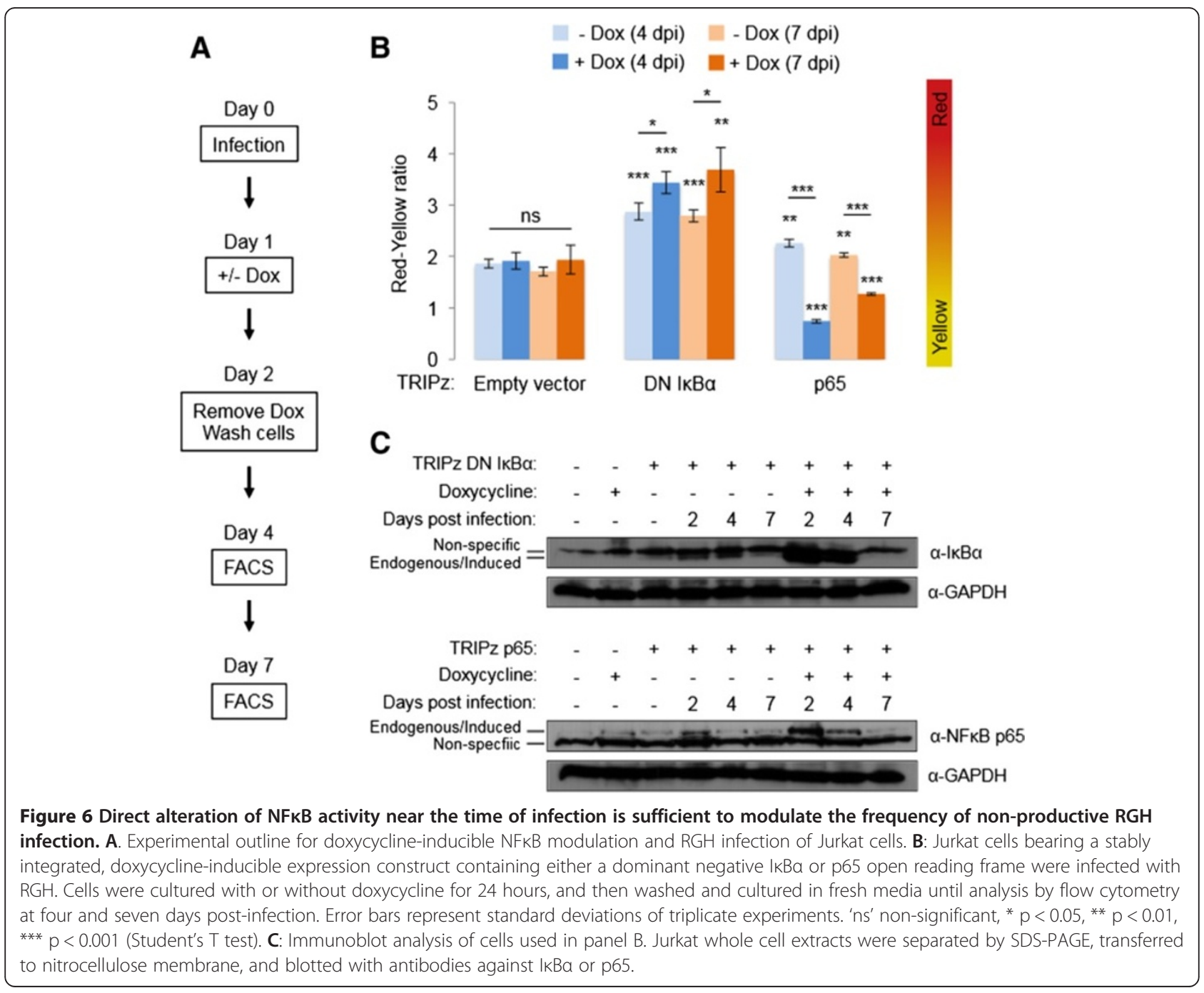


bearing the $\mathrm{DN} I \kappa \mathrm{B} \alpha$ and $\mathrm{p} 65$ expression constructs still showed a significant change in the occurrence of productively and non-productively infected cells ('red-yellow-ratio') seven days post-infection (Figure 6B). This further supports the idea that modulating $\mathrm{NFKB}_{\mathrm{B}}$ activity near the time of infection alters the fate of productive $\mathrm{RGH}$ infection on a permanent basis.

\section{The determination of productive RGH infection occurs around the time of infection}

Modulating $\mathrm{NF}_{k} \mathrm{~B}$ activity at the time of infection altered the proportion of non-productive $\mathrm{RGH}$ infections days later (Figures 5 and 6). Therefore, we wanted to determine the time frame in which infection productivity is amenable to permanent modification by TNF $\alpha$ treatment. We reasoned that if a window of opportunity existed to alter the infection productivity, treatment of cells with TNF $\alpha$ outside of this window should only have transient effects on the productivity of RGH infection. To test this, we infected cells with $\mathrm{RGH}$ and treated them with either DMSO or TNF $\alpha$ at four days post-infection rather than at the time of infection. 24 hours post TNF $\alpha$ treatment, a portion of cells were analyzed by flow cytometry (to check for LTR induction), while the remaining cells were allowed to recover for another four days. Similar to TNF $\alpha$ treatment at the time of infection (Figures 5A and B), treatment with TNF $\alpha$ four days post-infection was able to reactivate a large proportion of non-productive proviruses, as demonstrated by a decrease in the size of the 'red' population, and a corresponding increase in the number of 'yellow' cells (Figure 7A). However, after a four day recovery, the DMSO and TNF $\alpha$ treated samples were largely indistinguishable in terms of the sizes of the 'red' and 'yellow' populations, suggesting that TNF $\alpha$ treatment at day four post-infection had not permanently altered the proportion of non-productively infected cells (Figure 7A). This data stands in contrast to the effect of treating cells with TNF $\alpha$ at the time of infection (Figures 5A and $\mathrm{B}$ ), which suggests that the formation of direct non-productive infection occurs during, or shortly after, proviral integration.

To further explore the timing of RGH infection productivity, and to minimize the confounding impact of viral state on cellular outgrowth in a mixed population, we repeated the TNF $\alpha$-treatment-recovery experiment with RGH infected Jurkat cells sorted into their constituent 'double negative', 'red', and 'yellow' subpopulations. In each of the 'double negative' and 'red' populations, TNF $\alpha$ treatment of sorted cells activated a substantial proportion of non-productive proviruses, as reflected in the increase in the number of 'yellow' cells (Figure 7B). As expected, TNF $\alpha$ treatment of the 'yellow' population had a minimal effect, as the majority of proviruses were already transcriptionally active (Figure 7B). Interestingly, when the sorted populations were left to recover for four days, the 'double negative', 'red', and 'yellow' TNF $\alpha$ treated cells all became indistinguishable from their matched DMSO treated pairs (Figure 7B). This data is consistent with results from the bulk RGH infected cells (Figure 7A). Of note, we did not observe major differences in the ratio of live cells (FSC/SSC) between DMSO and TNF $\alpha$ treatments, suggesting that HIV-induced celltoxicity is not a substantial issue (data not shown). Furthermore, these findings collectively support the idea that non-productive $\mathrm{RGH}$ infection is established early (within four days post-infection) and permanently, such that TNF $\alpha$ treatment applied after the infection can no longer permanently alter the proportion of nonproductively infected cells.

\section{Discussion}

Despite extensive knowledge of individual mechanisms of HIV-1 transcriptional regulation, our understanding of the critical determinants for HIV-1 latency establishment in newly infected cells is limited. This knowledge gap is largely due to the inability to accurately identify latently infected cells early post-infection, and in their native state (i.e. without inducing cellular and viral activation). To circumvent these road-blocks, we and others have recent developed 'double-labeled' HIV-1 vectors incorporating constitutive markers of infection [5,6]. Initial studies with these models have revealed that a large proportion of HIV-1 infections result in a direct latent state, however the mechanisms by which these infections form remains unknown. In this study we used a doubly labeled HIV-1 latency model [5] to show that the cellular activation state and NFKB activity around the time of infection, but not viral integration site, are important for regulating direct non-productive infections in Jurkat T-cells.

Although primary CD4+ T-cells are considered to be the gold standard for HIV-1 latency models, we note a number of technical issues precluding the precise and unbiased evaluation of direct non-productive $\mathrm{RGH}$ infection in resting CD4+ T-cells. Nevertheless, we previously observed that $\mathrm{RGH}$ infection of activated primary CD4+ T-cells from three donors results in a high degree of direct non-productive infection, comparable to Jurkat cells [5]. Furthermore, another group also noted a high degree of latency in activated primary CD4+ T-cells [8]. This suggests that activated primary $\mathrm{CD} 4+\mathrm{T}$-cell infections may be accurately recapitulated in Jurkat cells. Thus, the results obtained with Jurkat cells in this study are likely to hold in primary T-cells, especially if primary cells must be activated in order to render them permissive to infection.

Previous reports have implicated integration site variability as a determinant for HIV-1 latency. Most notably, latency was correlated with integration into gene deserts, highly transcribed genes (high transcriptional interference) and alphoid repeats [11,12,37]. However, high-throughput 


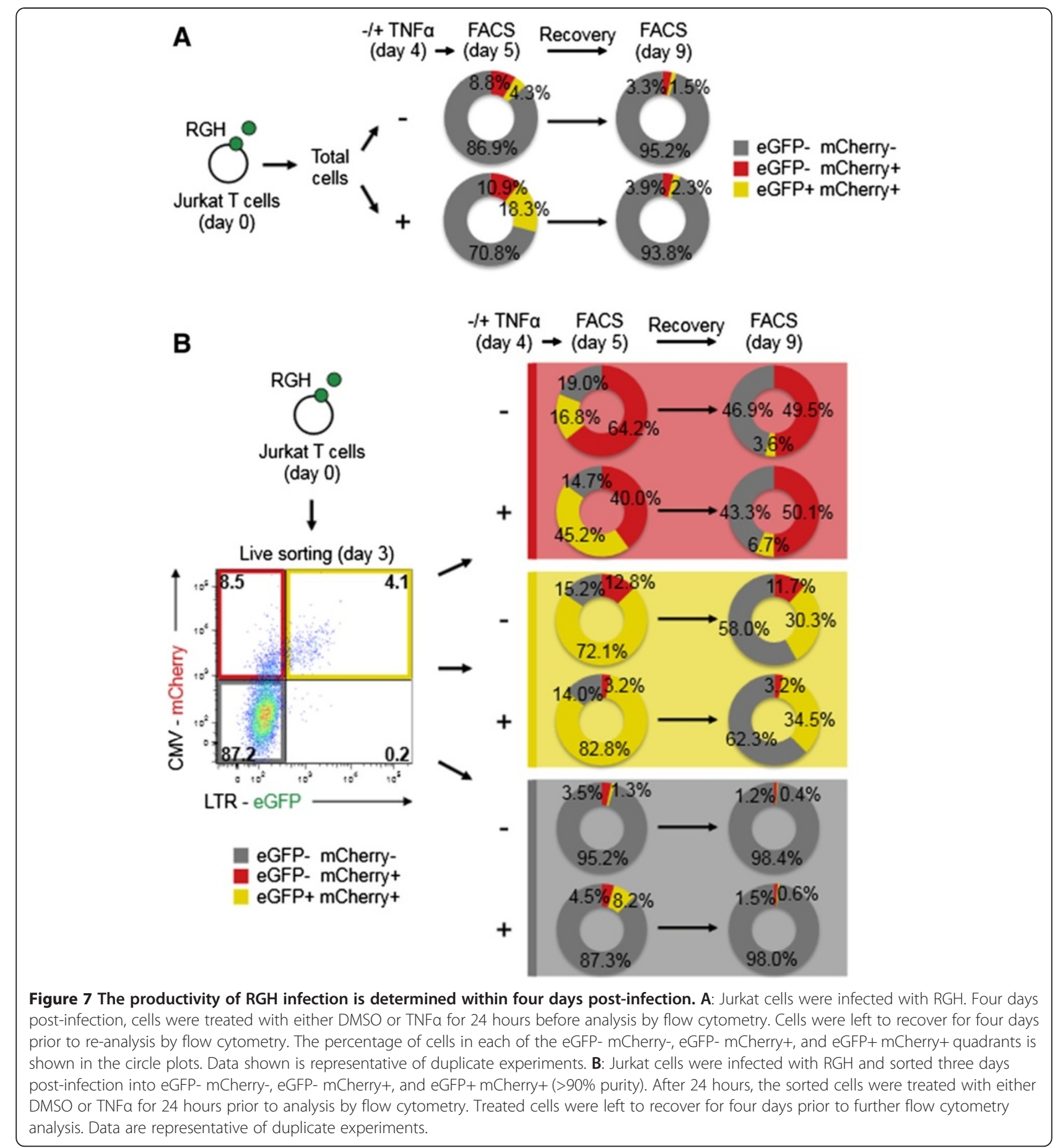

analysis of HIV-1 integration sites indicates that integrations into such regions are highly disfavored $[9,10]$. Instead, most proviruses are located within actively transcribed genes that are enriched for histone marks associated with active chromatin (H3K4me3, lysine acetylation), and depleted for marks associated with repressive chromatin (H3K9me3, H3K27me3) [9,10,12,38,39]. We speculate that latency models using cellular activation and long-term culturing to identify and establish latency could select for the most strongly repressed latent proviruses, thereby resulting in an over-representation of such disfavored integration locations. Our analysis of proviral locations in $\mathrm{RGH}$ infected Jurkat cells shows little evidence for integration sites regulating the difference between 'red' (eGFPmCherry+) and 'yellow' (eGFP+ mCherry+) cells (Figures 2 and 3, S1, and S2). Furthermore we did not find any 
evidence for enrichment of the aforementioned rare types of integration sites. Moreover, the frequency at which these types of integrations occur is incompatible with the degree of direct non-productive infections observed in the $\mathrm{RGH}$ model [5] and by other groups [6-8]. Our conclusions are in agreement with a recent meta-analysis of HIV-1 integration sites in five primary and cell line latency models [13]. In this study, the authors found no genomic predictors of latency and, interestingly, only little overlap of chromosomal features between latency models [13]. This highlights the intrinsic mechanistic variability of HIV-1 latency models, as well as the need to fully characterize determinants of latency in each model.

In the absence of a role for integration sites in regulating direct non-productive RGH infection in newly infected Jurkat cells, the data presented in this study suggest that productive infection is positively correlated with cellular activation and $\mathrm{NF}_{k} \mathrm{~B}$ activity (Figures 4, 5, 6, 7, and 8). Despite this understanding, it remains to be determined what drives fluctuations in cellular activity and corresponding NFKB activity within any given population of newly infected cells. In the physiological context of T-cells, the timing of infection during cellular deactivation (reversion from activated state to memory state) is a plausible driver of activation state heterogeneity [1]. Depending on the time of infection, cells may be at different points in the deactivation process

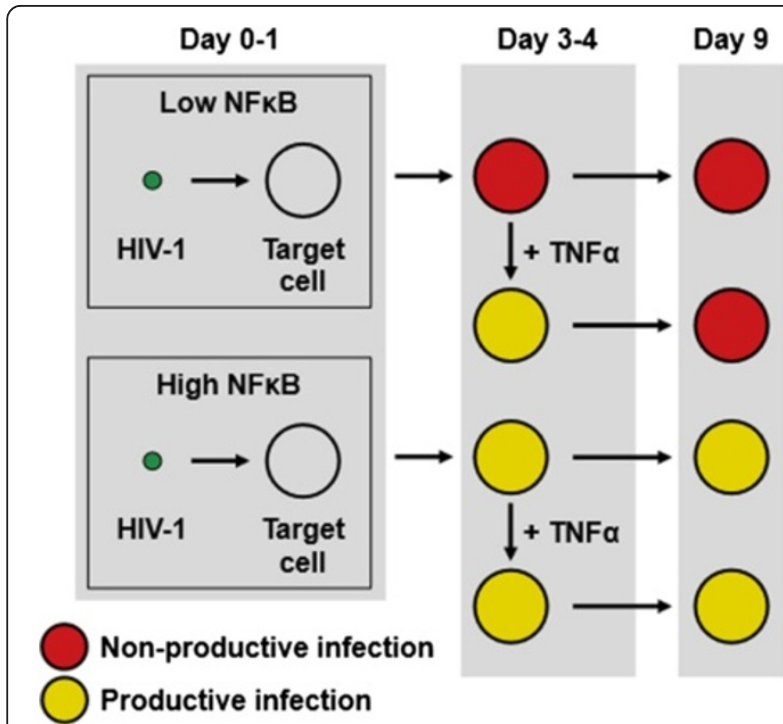

Figure 8 Model of NFKB mediated effects on RGH productivity in newly infected cells. Schematic representation of productive infection determination in RGH infected Jurkat cells. In cells with low NFKB activity, the majority of RGH infected cells exist in a nonproductive state (eGFP- mCherry+, 'red') four days post infection, whereas cells with high NFKB activity have a greater propensity to exist in a productive state (eGFP+ mCherry+, 'yellow') and persist over time. TNFa stimulation of non-productively infected cells four days post infection only temporarily reactivates HIV-1, which reverts to its non-productive state days later. and newly integrated proviruses may be exposed to highly variable $\mathrm{T}$-cell signaling states and/or transcription factor pools. Complementary to this, thermodynamically driven stochastic fluctuations in cellular processes, which can drive phenotypic asymmetry in clonal cells (reviewed in $[40,41]$ ), may impact NFkB activity. Indeed, the NFkB and SP1 sites of the LTR have been implicated in controlling stochastic HIV-1 gene expression noise [42]. Other potential mechanisms of $\mathrm{NFKB}_{\mathrm{B}}$ fluctuation include oscillatory behavior in response to TNF $\alpha$ signaling [43], and rapid nuclear shuttling of NFkB p65 and IkB $\alpha$ [44]. NFkB p65 shuttling was shown to provide low-level basal HIV-1 transcription in infected resting CD4+ T-cells [44], while shuttling of IkB $\alpha$ was shown to dampen leaky $\mathrm{NF} \mathrm{B}$ signaling by removing active NFkB p65 from the nucleus $[44,45]$. Taken together, the cumulative action of several sources of fluctuation could contribute to a wide spectrum of cellular activation and $\mathrm{NF}_{k \mathrm{~B}}$ activity in vivo. Further work is needed to elucidate exactly what cellular state and $\mathrm{NF}$ B B activity level is deterministic for primary latency establishment.

Our data indicate that direct non-productive infections are established around the time of infection, and that this process is fundamentally different from latency in which productive infections are silenced over time (Figures 5, 6, 7, and 8). We note that treatments with $\mathrm{NF} \kappa \mathrm{B}$ agonists and antagonists early during infection could profoundly alter the occurrence of non-productive infection days later, whereas treatment four days post-infection did not result in long term modulation (Figures 7 and 8). This indicates that once a non-productive state is established during initial infection, it becomes 'imprinted', possibly through subsequent epigenetic modifications (Figure 8).

Our results contribute to an emerging body of work that links cellular activation state and transcription factor availability with the formation of HIV-1 latency. Although evidence is mounting that $\mathrm{NFKB}$ contributes to latency determination in newly infected cells (this study and [7]), we cannot exclude the actions of other transcription factors and/or upstream regulators in modulating latency. Most notably, the factors SP1 [42], AP1 [46], and the Jun $\mathrm{N}$-terminal protein kinase (JNK) $[47,48]$ have all been implicated in HIV-1 latency. It will be of great benefit to reconcile these studies and develop a comprehensive understanding of how individual factors/mechanisms act cumulatively to establish latency in newly infected cells. Indeed, fully understanding this process is paramount to successfully devising biologically relevant model systems suitable for screening novel latency modulating therapeutics.

\section{Conclusions}

HIV-1 infection of Jurkat T-cells results in both productive and non-productive proviral states shortly after infection. Our data indicate that the differences between productive 
and non-productive infections are not caused by the location or orientation of viral integrations. Instead, the cellular activation state and NFKB activity around the time of infection determine the outcome of viral infections and, in turn, early latency.

\section{Methods}

\section{Viral vectors and constructs}

The Red-Green-HIV-1 (RGH) molecular clone was used as previously described [5]. To construct the gag-N74D RGH clone, the mutation was created by PCR mediated site directed mutagenesis and cloning of the amplicon into the BspQI/ApaI sites of the previously described $\mathrm{RGH}$ construct [5]. The Red-Blue-HIV-1 (RBH) molecular clone was created by cloning a synthesized tagBFP construct (GeneWiz) into the SapI/SphI sites of RGH.

pTRIPz-EV, pTRIPz-DN-IkB $\alpha$ and pTRIPz-p65 are derivatives of the commercial doxycycline-inducible lentiviral vector pTRIPZ-Ctrl (Thermo Fisher). pTRIPz-EV (empty vector) was created by digestion with AgeI/ MluI, blunting with Klenow polymerase, and re-ligation. pTRIPz-DN-IkB $\alpha$ contains the S32A/S36A mutant version of the IkB $\alpha$ repressor PCR amplified from pSVK3IKB $\alpha-2 \mathrm{~N}$ [36], which was cloned into the AgeI/MluI sites of pTRIPz-Ctrl. pTRIPz-p65 contains a PCR amplified NFkB p65 open reading frame cloned into the AgeI/MluI sites of pTRIPz-Ctrl.

\section{Cell culture, virion production, and transduction}

Jurkat E6-1 [49], HEK293T (ATCC), and derivative cell lines created in this study were cultured as previously described [5]. VSV-G pseudotyped viral stocks were created by transfecting HEK293T cells with envelope deleted viral molecular clones and pHEF-VSVg [50] in a 10:1 ratio as previously described [5]. Unless otherwise indicated, Jurkat E6-1 cells were spinoculated as previously described [5]. Briefly, $5 \times 10^{5}$ cells in $1 \mathrm{~mL}$ culture media $(+4 \mu \mathrm{g} / \mathrm{mL}$ polybrene) were spin-infected $(1.5 \mathrm{hr}, 500 \times g$, room temperature) with $25 \mu \mathrm{L}$ of viral stock, so as to yield an average infection rate of than $10-15 \%$ and ensure singlecopy integrations.

NFkB-eGFP viral stocks were produced in HEK293T cells by co-transfecting pGreenFire1-NF- $\mathrm{B}$ (Systems Biosciences), pHEF-VSVg [50], pLP1-gag/pol, pLP2-Rev, and pcDNA3.1+-Tat $(2 \mu \mathrm{g}$ each, $30 \mu \mathrm{g}$ polyethylenimine reagent). Purified and concentrated viral stocks were prepared as previously described [5]. NFkB reporter cell lines were created by transducing Jurkat cells with NFkB-eGFP virus $(\mathrm{MOI} \sim 4)$, followed by puromycin selection $(1 \mu \mathrm{g} / \mathrm{mL}$ - Clontech). Resistant cells were subsequently maintained in complete media supplemented with $0.5 \mu \mathrm{g} / \mathrm{mL}$ puromycin.

pTRIPz viral stocks and stable cell lines were produced as described above for NFKB-eGFP, except that the lentiviral vectors pTRIPz-EV, pTRIPz-DN-IkB $\alpha$ or pTRIPz-p65 were used.

\section{Flow cytometry and staining}

Analysis of infected cells by flow cytometry and live cell sorting were performed as previously described [5]. Of note, in all experiments, analysis was limited to live cells by FSC/SSC gating at the time of data acquisition. Unless otherwise stated, infected cells were analyzed four days post-infection. Jurkat E6-1 cells were stained and analyzed for CD69 as previously described [51] except that antibodies were conjugated to $\mathrm{PE}-\mathrm{Cy} 7$ and $1 \mu \mathrm{L}$ of antibody was used per $1 \times 10^{5}$ cells (BD Biosciences). Jurkat cells were stained with PE-Cy7-NFkB p65 (pS529) (BD Biosciences) and NFKB p50 (Abcam) with Pacific Blue conjugated secondary antibody (Life Technologies) as previously described [52].

\section{Compound treatments}

Infected cells were treated with the various compounds for the times and durations indicated in individual experiments. Compounds were added at the listed concentrations to complete media. Unless otherwise stated, compounds were used at the following concentrations: TNF $\alpha, 10 \mathrm{ng} / \mathrm{mL}$ (Sigma); SAHA, $0.5 \mu \mathrm{M}$ [53]; PMA, $4 \mathrm{ng} / \mathrm{mL}$ (Sigma); Ionomycin, $1 \mu \mathrm{M}$ (Sigma), BMS345541, 5 нM (Sigma).

\section{Pyrosequencing of integration sites}

HIV-1 integration sites were analyzed by 454 deepsequencing as previously described [14]. Briefly, Jurkat cells were infected with RGH and sorted into constituent populations three days post-infection (eGFP- mCherry-, eGFP- mCherry+, eGFP+ mCherry+). Genomic DNA was extracted from $\sim 5 \times 10^{5}$ cells of each population, digested with MseI and ligated to adaptors. Nested PCR with adapter and LTR specific primers was performed to amplify the HIV-host genome junctions. After gel extraction of 100-600 bp fragments, amplicons were subjected to pyrosequencing on a $454 \mathrm{GS}$ Junior machine (Roche). Data was analyzed using the Integration Site Pipeline and Database (INSIPID) web tool (Bushman Lab - http://microb215. med.upenn.edu/Insipid/ - [10,15], Circos [54], SeqMonk software (http://www.bioinformatics.babraham.ac.uk/projects/ seqmonk/), WebLogo3 (http://weblogo.threeplusone.com/ create.cgi), and the R/Bioconductor package 'goProfiles' (http://bioconductor.org/packages/2.11/bioc/html/goProfiles. html).

\section{Immunoblotting}

RGH infected Jurkat cells were lysed in NP-40 lysis buffer $(50 \mathrm{mM}$ Tris, $\mathrm{pH} 8.0,150 \mathrm{mM} \mathrm{NaCl}, 1 \%$ (v/v) NP-40, 0.1\% (w/v) SDS) supplemented with 1x protease inhibitor cocktail (Roche). Lysates were cleared by 
centrifugation $\left(10 \mathrm{~min}, 16000 \times g, 4^{\circ} \mathrm{C}\right)$, mixed with $4 \times$ SDS-PAGE sample buffer, and boiled for $5 \mathrm{~min}$. Whole cell extracts $(40 \mu \mathrm{g})$ were separated on a $12 \%$ SDS-PAGE gel and then transferred to nitrocellulose membrane. Membranes were blocked with $2 \%(\mathrm{w} / \mathrm{v})$ BSA in PBSTween $(0.05 \% \mathrm{v} / \mathrm{v})$ and then incubated with primary antibody overnight at $4{ }^{\circ} \mathrm{C}$. Antibodies used were as follows: ІкBa - Abcam 32518 [1:5000], NFкB p65 Abcam 7970 [1:500], GAPDH - Abcam 9484 [1:4000]. After washing and incubation with HRP conjugated secondary antibody, membranes were washed and signal was developed with SuperSignal West Femto chemiluminescent substrate (Thermo Fisher).

\section{Statistical analysis}

Unless otherwise stated, experiments were performed in biological triplicate. Where appropriate, statistical inference was performed on quantitative data. Two group testing was performed using the Student's T-test, while comparison between multiple groups was made using one-way-ANOVA followed by pairwise two-group testing (Student's T-test). Statistical analysis was performed in R 2.15.1 (http://www.r-project.org/). Integration site analysis heatmaps were created using the INSIPID pipeline (Figures 3A and Additional file 1: Figure S1B) utilizing previously described statistical methodology $[10,15]$. Briefly, for each identified integration site, matched random controls were created in silico. This pairing of experimental and control sites allows for computation of relative enrichment and de-enrichment profiles using a receiver operating characteristic framework. Comparisons between sets of integration sites (samples) for statistical significance are performed by calculating Wald-type test statistics, which are then tested using Chi Square methods.

\section{Additional files}

Additional file 1: Figure S1. Productive and non-productive RGH infections occur regardless of epigenetic properties at sites of integration A: Epigenetic properties of identified integration sites were compared between samples using the INSIPID heatmap tool for epigenetic features (Bushman Lab, University of Pennsylvania). Included features were limited to those identified in high-throughput studies of Jurkat and primary CD4+ T-cells. Yellow and blue colors represent depletion and enrichment of each feature, respectively, relative to matched random controls of integration sites. Statistical significance (ranked Wald tests) is shown relative to the eGFP+ mCherry+ population (dashes). B: Proviral integrations across the entire human genome are plotted as a function of the average distance across gene bodies ( $5^{\prime}$ to $3^{\prime}$ - top panel), and the average distance from gene transcriptional start sites (TSS - bottom panel). Data are plotted as pale filled circles with darker smoothed lines (Loess) overlaid. C: Jurkat cells were infected with equal amounts of wildtype RGH or an RGH version containing an N74D mutation in Capsid. Cells were analyzed by flow cytometry four days post-infection. Representative plots (left) and graphical quantitation (right) are shown. Error bars represent standard deviations of triplicate experiments. 'ns' nonsignificant.
Additional file 2: Figure S2. Productive and non-productive RGH infections occur regardless of DNA sequence at the point of integration or functional annotation of host genes. A: Weblogo3 analysis of the DNA sequence $(+/-20 \mathrm{bp})$ surrounding each integration site in the eGFP- mCherry- ('double negative'), eGFP- mCherry+ ('red'), and eGFP+ mCherry+ ('yellow') populations. B: Gene ontology analysis of integration sites in the eGFP- mCherry- ('double negative'), eGFP- mCherry+ ('red'), and eGFP+ mCherry+ ('yellow') populations, using goProfiles.

Additional file 3: Figure S3. RGH infection does not induce cellular activation or NFkB signaling. A. Mock- and total-RGH-infected Jurkat cells were stained for CD69 four days post-infection. Data shown is representative of triplicate experiments. B. Mock- and total-RGH-infected Jurkat cells were stained for either NFkB p50 or NFkB p65-S529phospho four days post-infection. Data shown is representative of triplicate experiments. C. Mock- and total-RBH-infected Jurkat NFkB-eGFP reporter cell lines 1-5 were analyzed by flow cytometry four days post-infection. Data shown is representative of multiple experiments.

Additional file 4: Figure S4. Characterization of RBH infection and Jurkat NFKB reporter cell lines. A: Jurkat NFKB reporter clones 2-5 were treated with DMSO, TNFa, or PMA/lonomycin for 24 hours prior to analysis by flow cytometry for eGFP mean fluorescence intensity (MFI). Error bars represent one standard error of the mean. B: Jurkat NFkB reporter clones $2-5$ were infected with $\mathrm{RBH}$ viral stock and analyzed by flow cytometry at four days post-infection. Cells were gated into their constituent infected populations and then analyzed for eGFP MFI. Error bars represent one standard error of the mean.

\section{Competing interests}

The authors declare that they have no competing interests.

\section{Authors' contributions}

MSD and MO conceived, designed and performed the experiments and analyzed the data. MSD, MO, VS and IS wrote the manuscript. CB, JT and PRH performed 454 deep sequencing. All authors read and approved the final manuscript.

\section{Acknowledgements}

We thank Andy Johnson and Justin Wong of the UBC Flow Cytometry Facility for live cell sorting and analysis. We thank Winnie Dong and Dennison Chan for assistance with pyrosequencing. We thank Nirav Milani for help with the INSIPID pipeline. We gratefully acknowledge Pauline Johnson for the lentiviral packaging accessory plasmids and Amy Saunders for assistance with CD69 staining. We thank Jacob Hodgson, Adam

Chruscicki, Kevin Eade, Benjamin Martin, and Nicolas Coutin for thoughtful discussions and review of this manuscript.

The following reagents were obtained through the AIDS Research and Reference Reagent Program, Division of AIDS, NIAID, NIH: Jurkat Clone E6-1 from Dr. Arthur Weiss, SAHA (Vorinostat), and pHEF-VSVG from Dr. Lung-Ji Chan.

This work was supported by Canadian Institute of Health Research (CIHR) grants to I.S. (MOP-77807, HOP-120237), NIH/NIAID grants to V.S. (Al064001, Al104406, Al90935). M.S.D is supported by a CIHR fellowship (CGD-96495). P.R.H. is supported by a CIHR/GSK chair in clinical virology at the University of British Columbia.

\section{Author details}

${ }^{1}$ Biochemistry and Molecular Biology, University of British Columbia, Vancouver, BC V6T1Z3, Canada. 'Department of Microbiology, The Global Health and Emerging Pathogens Institute; Mount Sinai School of Medicine, 1468 Madison Avenue, Annenberg building 18-50, New York, NY 10029, USA. ${ }^{3}$ Division of Infectious Diseases, Department of Medicine, Mount Sinai School of Medicine, New York, NY 10029, USA. ${ }^{4}$ BC Centre for Excellence in HIV/ AIDS, Vancouver, BC V6Z1Y6, Canada.

Received: 20 August 2013 Accepted: 4 February 2014 Published: 7 February 2014

\section{References}

1. Donahue DA, Wainberg MA: Cellular and molecular mechanisms involved in the establishment of HIV-1 latency. Retrovirology 2013, 10:11. 
2. Siliciano RF, Greene WC: HIV latency. Cold Spring Harb Perspect Biol 2011, 1:a007096

3. Karn J, Stoltzfus CM: Transcriptional and posttranscriptional regulation of HIV-1 gene expression. Cold Spring Harb Perspect Biol 2012, 2:a006916.

4. Finzi D, Hermankova M, Pierson T, Carruth LM, Buck C, Chaisson RE, Quinn TC, Chadwick K, Margolick J, Brookmeyer R, Gallant J, Markowitz M, Ho DD, Richman DD, Siliciano RF: Identification of a reservoir for HIV-1 in patients on highly active antiretroviral therapy. Science 1997, 278:1295-1300.

5. Dahabieh MS, Ooms M, Simon V, Sadowski I: A doubly fluorescent HIV-1 reporter shows that the majority of integrated HIV-1 is latent shortly after infection. J Virol 2013, 87:4716-4727.

6. Calvanese V, Chavez L, Laurent T, Ding S, Verdin E: Dual-color HIV reporters trace a population of latently infected cells and enable their purification. Virology 2013, 446:283-292

7. Duverger A, Jones J, May J, Bibollet-Ruche F, Wagner FA, Cron RQ, Kutsch O: Determinants of the establishment of human immunodeficiency virus type 1 latency. J Virol 2009, 83:3078-3093.

8. van der Sluis RM, van Montfort T, Pollakis G, Sanders RW, Speijer D, Berkhout $B$, Jeeninga RE: Dendritic cell-induced activation of latent HIV-1 provirus in actively proliferating primary T lymphocytes. PLOS Pathog 2013, 9:e1003259.

9. Wang GP, Ciuffi A, Leipzig J, Berry CC, Bushman FD: HIV integration site selection: analysis by massively parallel pyrosequencing reveals association with epigenetic modifications. Genome Res 2007, 17:1186-1194.

10. Brady T, Agosto LM, Malani N, Berry CC, O'Doherty U, Bushman F: HIV integration site distributions in resting and activated CD4+ T cells infected in culture. AIDS 2009, 23:1461-1471.

11. Jordan A, Bisgrove D, Verdin E: HIV reproducibly establishes a latent infection after acute infection of T cells in vitro. EMBO J 2003, 22:1868-1877.

12. Lewinski MK, Bisgrove D, Shinn P, Chen H, Hoffmann C, Hannenhalli S, Verdin E, Berry CC, Ecker JR, Bushman FD: Genome-wide analysis of chromosomal features repressing human immunodeficiency virus transcription. J Virol 2005, 79:6610-6619.

13. Sherrill-Mix S, Lewinski MK, Famiglietti M, Bosque A, Malani N, Ocwieja KE, Berry CC, Looney D, Shan L, Agosto LM, Pace MJ, Siliciano RF, O'Doherty U, Guatelli J, Planelles V, Bushman FD: HIV latency and integration site placement in five cell-based models. Retrovirology 2013, 10:90.

14. Ciuffi A, Barr SD: Identification of HIV integration sites in infected host genomic DNA. Methods 2011, 53:39-46.

15. Berry C, Hannenhalli S, Leipzig J, Bushman FD: Selection of target sites for mobile DNA integration in the human genome. PLoS Comput Biol 2006, 2:e157.

16. Su Al, Cooke MP, Ching KA, Hakak Y, Walker JR, Wiltshire T, Orth AP, Vega RG, Sapinoso LM, Mogrich A, Patapoutian A, Hampton GM, Schultz PG, Hogenesch JB: Large-scale analysis of the human and mouse transcriptomes. Proc Natl Acad Sci 2002, 99:4465-4470.

17. Wang Z, Zang C, Rosenfeld JA, Schones DE, Barski A, Cuddapah S, Cui K, Roh T-Y, Peng W, Zhang MQ, Zhao K: Combinatorial patterns of histone acetylations and methylations in the human genome. Nat Genet 2008, 40:897-903.

18. Schones DE, Cui K, Cuddapah S, Roh T-Y, Barski A, Wang Z, Wei G, Zhao K: Dynamic regulation of nucleosome positioning in the human genome. Cell 2008, 132:887-898.

19. Jothi R, Cuddapah S, Barski A, Cui K, Zhao K: Genome-wide identification of in vivo protein-DNA binding sites from ChIP-Seq data. Nucleic Acids Res 2008, 36:5221-5231.

20. Robertson AG, Bilenky M, Tam A, Zhao Y, Zeng T, Thiessen N, Cezard T, Fejes AP, Wederell ED, Cullum R, Euskirchen G, Krzywinski M, Birol I, Snyder M, Hoodless PA, Hirst M, Marra MA, Jones SJM: Genome-wide relationship between histone $\mathrm{H} 3$ lysine 4 mono- and tri-methylation and transcription factor binding. Genome Res 2008, 18:1906-1917.

21. Wang Z, Zang C, Cui K, Schones DE, Barski A, Peng W, Zhao K: Genome-wide mapping of HATs and HDACs reveals distinct functions in active and inactive genes. Cell 2009, 138:1019-1031.

22. Cui K, Zang C, Roh T-Y, Schones DE, Childs RW, Peng W, Zhao K. Chromatin signatures in multipotent human hematopoietic stem cells indicatethe fate of bivalent genes during differentiation. Stem Cell 2009, 4:80-93.

23. Meylan S, Groner AC, Ambrosini G, Malani N, Quenneville S, Zangger N, Kapopoulou A, Kauzlaric A, Rougemont J, Ciuffi A, Bushman FD, Bucher P,
Trono D: A gene-rich, transcriptionally active environment and the pre-deposition of repressive marks are predictive of susceptibility to KRAB/KAP1- mediated silencing. BMC Genomics 2011, 12:378.

24. Koh Y, Wu X, Ferris AL, Matreyek KA, Smith SJ, Lee K, Kewalramani VN, Hughes SH, Engelman A: Differential effects of human immunodeficiency virus type 1 capsid and cellular factors nucleoporin 153 and LEDGF/p75 on the efficiency and specificity of viral DNA integration. J Virol 2013, 87:648-658.

25. Schaller T, Ocwieja KE, Rasaiyaah J, Price AJ, Brady TL, Roth SL, SEP H e, Fletcher AJ, Lee K, Kewalramani VN, Noursadeghi M, Jenner RG, James LC, Bushman FD, Towers G: HIV-1 capsid-cyclophilin interactions determine nuclear import pathway. Integration targeting and replication efficiency. PLoS Pathog 2011, 7:e1002439.

26. Ocwieja KE, Brady TL, Ronen K, Huegel A, Roth SL, Schaller T, James LC, Towers GJ, Young JAT, Chanda SK, Konig R, Malani N, Berry CC, Bushman FD: HIV integration targeting: a pathway involving Transportin-3 and the nuclear pore protein RanBP2. PLoS Pathog 2011, 7:e1001313.

27. Han Y, Lin YB, An W, Xu J, Yang H-CC, O'Connell K, Dordai D, Boeke JD, Siliciano JD, Siliciano RF: Orientation-dependent regulation of integrated HIV-1 expression by host gene transcriptional readthrough. Cell Host Microbe 2008, 4:134-146.

28. Lenasi T, Contreras X, Peterlin BM: Transcriptional interference antagonizes proviral gene expression to promote HIV latency. Cell Host Microbe 2008, 4:123-133.

29. Shan L, Yang HC, Rabi SA, Bravo HC, Shroff NS, Irizarry RA, Zhang H, Margolick JB, Siliciano JD, Siliciano RF: Influence of host gene transcription level and orientation on HIV-1 latency in a primary-cell model. J Virol 2011, 85:5384-5393.

30. Chan JKL, Greene WC: NF-KB/Rel: agonist and antagonist roles in HIV-1 latency. Curr Opin HIV AIDS 2011, 6:12-18.

31. Lopez-Cabrera M, Munoz E, MV B z, Ursa MA, Santis AG, Sanchez-Madrid F: Transcriptional regulation of the gene encoding the human C-type lectin leukocyte receptor AIM/CD69 and functional characterization of its tumor necrosis factor-alpha-responsive elements. J Biol Chem 1995, 270:21545-21551.

32. Archin NM, Espeseth A, Parker D, Cheema M, Hazuda D, Margolis DM: Expression of latent HIV induced by the potent HDAC inhibitor suberoylanilide hydroxamic acid. AIDS Res Hum Retrovir 2009, 25:207-212

33. Archin NM, Liberty AL, Kashuba AD, Choudhary SK, Kuruc JD, Crooks AM, Parker DC, Anderson EM, Kearney MF, Strain MC, Richman DD, Hudgens MG, Bosch RJ, Coffin JM, Eron JJ, Hazuda DJ, Margolis DM: Administration of vorinostat disrupts HIV-1 latency in patients on antiretroviral therapy. Nature 2012, 487:482-485.

34. Van Lint C, Emiliani S, Verdin E: The expression of a small fraction of cellular genes is changed in response to histone hyperacetylation. Gene Expr 1996, 5:245-253.

35. Chen G, Goeddel DV: TNF-R1 signaling: a beautiful pathway. Science 2002, 296:1634-1635.

36. Kwon H, Pelletier N, DeLuca C, Genin P, Cisternas S, Lin R, Wainberg MA Hiscott J: Inducible expression of IKBa repressor mutants interferes with NF-KB activity and HIV-1 replication in Jurkat T cells. J Biol Chem 1998, 273:7431-7440.

37. Jordan A, Defechereux P, Verdin E: The site of HIV-1 integration in the human genome determines basal transcriptional activity and response to Tat transactivation. EMBO J 2001, 20:1726-1738.

38. Han Y, Lassen K, Monie D, Sedaghat AR, Shimoji S, Liu X, Pierson TC, Margolick JB, Siliciano RF, Siliciano JD: Resting CD4+ T cells from human immunodeficiency virus type 1 (HIV-1)-infected individuals carry integrated HIV-1 genomes within actively transcribed host genes. J Virol 2004, 78:6122-6133.

39. Wang GP, Levine BL, Binder GK, Berry CC, Malani N, McGarrity G, Tebas P, June $\mathrm{CH}$, Bushman FD: Analysis of lentiviral vector integration in HIV + study subjects receiving autologous infusions of gene modified CD4+ T cells. Mol Ther 2009, 17:844-850.

40. Raj A, van Oudenaarden A: Nature, nurture, or chance: stochastic gene expression and its consequences. Cell 2008, 135:216-226.

41. Raser JM, O'Shea EK: Noise in gene expression: origins, consequences, and control. Science 2005, 309:2010-2013.

42. Burnett JC, Miller-Jensen K, Shah PS, Arkin AP, Schaffer DV: Control of stochastic gene expression by host factors at the HIV promoter. PLoS Pathog 2009, 5:e1000260. 
43. Nelson DE, Ihekwaba AEC, Elliott M, Johnson JR, Gibney CA, Foreman BE, Nelson G, See V, Horton CA, Spiller DG, Edwards SW, McDowell HP, Unitt JF, Sullivan E, Grimley R, Benson N, Broomhead D, Kell DB, White MRH: Oscillations in NF-KB signaling control the dynamics of gene expression. Science 2004, 306:704-708.

44. Coiras M, Lopez-Huertas MR, Rullas JIN, Mittelbrunn M, Alcami J, Lopez-Huertas MIAR, Rullas JIN, Mittelbrunn M, Alcami JE: Basal shuttle of NFKB/lkBa alpha in resting T lymphocytes regulates HIV-1 LTR dependent expression. Retrovirology 2007, 4:56.

45. Arenzana-Seisdedos F, Turpin P, Rodriguez M, Thomas D, Hay RT, Virelizier $\mathrm{JL}$, Dargemont C: Nuclear localization of IkBa promotes active transport of NF-KB from the nucleus to the cytoplasm. J Cell Sci 1997, 3:369-378.

46. Duverger A, Wolschendorf F, Zhang M, Wagner F, Hatcher B, Jones J, Cron $R Q$, van der Sluis RM, Jeeninga RE, Berkhout B, Kutsch O: An AP-1 binding site in the enhancer/core element of the HIV-1 promoter controls the ability of HIV-1 to establish latent infection. J Virol 2013, 87:2264-2277.

47. Wolschendorf F, Bosque A, Shishido T, Duverger A, Jones J, Planelles V, Kutsch O: Kinase control prevents HIV-1 reactivation in spite of high levels of induced NF-kB activity. J Virol 2012, 86:4548-4558.

48. Duverger A, Wolschendorf F, Anderson JC, Wagner F, Bosque A, Shishido T, Jones J, Planelles V, Willey C, Cron RQ, Kutsch O: Kinase control of Latent HIV-1 Infection: PIM-1 Kinase as a Major Contributor to HIV-1 Reactivation. J Virol 2014, 88:364-376.

49. Weiss A, Wiskocil RL, Stobo JD: The role of T3 surface molecules in the activation of human T cells: a two-stimulus requirement for IL 2 production reflects events occurring at a pre-translational level. J Immunol 1984, 133:123-128.

50. Chang $\sqcup$, Urlacher V, Iwakuma T, Cui Y, Zucali J: Efficacy and safety analyses of a recombinant human immunodeficiency virus type 1 derived vector system. Gene Ther 1999, 6:715-728.

51. Bernhard W, Barreto K, Saunders A, Dahabieh MS, Johnson P, Sadowski I: The Suv39H1 methyltransferase inhibitor chaetocin causes induction of integrated HIV-1 without producing a T cell response. FEBS Lett 2011, 585:3549-3554.

52. Grupillo M, Lakomy R, Geng X, Styche A, Rudert WA, Trucco M, Fan Y: An improved intracellular staining protocol for efficient detection of nuclear proteins in YFP-expressing cells. Biotechniques 2011, 51:417-420.

53. Marks PA, Breslow R: Dimethyl sulfoxide to vorinostat: development of this histone deacetylase inhibitor as an anticancer drug. Nat Biotechnol 2007, 25:84-90.

54. Krzywinski MI, Schein JE, Birol I, Connors J, Gascoyne R, Horsman D, Jones SJ, Marra MA: Circos: An information aesthetic for comparative genomics. Genome Res 2009, 19:1639-1645.

doi:10.1186/1742-4690-11-17

Cite this article as: Dahabieh et al:: Direct non-productive HIV-1 infection in a T-cell line is driven by cellular activation state and NFKB. Retrovirology 2014 11:17

\section{Submit your next manuscript to BioMed Central and take full advantage of:}

- Convenient online submission

- Thorough peer review

- No space constraints or color figure charges

- Immediate publication on acceptance

- Inclusion in PubMed, CAS, Scopus and Google Scholar

- Research which is freely available for redistribution 